\title{
Integración crítica de las tecnologías emergentes en la formación docente: Mirando hacia el futuro
}

\author{
Critical Integration of Emerging Technologies in Teacher Education: Looking to the Future
}

Integração crítica de tecnologias emergentes na formação de professores: Olhando para o futuro

Susana Jiménez-Sánchez

Universidad Nacional

ROR:: https://ror.org/01t466c14

Heredia, Costa Rica

susana.jimenez.sanchez@una.ac.cr

https://orcid.org/0000-0001-6830-1772

\begin{abstract}
Resumen: Dado que las tecnologías emergentes estarán presentes en el futuro educativo, en el Centro de Investigación y Docencia en Educación (CIDE) de la Universidad Nacional, Costa Rica, debemos trabajar desde la formación docente, en procesos donde estas se integren en la práctica pedagógica y se logre un aprendizaje significativo crítico.
\end{abstract}

Palabras claves: Tecnologías emergentes; formación docente; futuro; COVID-19.

\begin{abstract}
Emerging technologies will be present in the educational future, for that reason at Centro de Investigación y Docencia en Educación (CIDE), from Universidad Nacional, Costa Rica, we must work from teacher training, in processes where that technologies are integrated into pedagogical practice and critical meaningful learning is achieved.
\end{abstract}

Keywords: Emerging technologies; teacher training; future; COVID-19.

Resumo: Como as tecnologias emergentes estarão presentes no futuro educacional, no Centro de Investigación y Docencia en Educación (CIDE) da Universidad Nacional, Costa Rica, devemos trabalhar a partir da formação de professores, em processos nos quais elas são integradas à prática pedagógica e a aprendizagem significativa e crítica é alcançada.

Palavras-chaves: Tecnologias emergentes; formação de profesores; futuro; COVID-19.

Recibido: 15/07/2020 Aceptado: 10/08/2020

\section{Introducción}

¿Cuál es el futuro educativo que pensamos y queremos? Esa es una pregunta clave para quienes nos dedicamos a la formación docente en el Centro de investigación y Docencia en Educación (CIDE) de la Universidad Nacional (UNA), Costa Rica, pues para lograrlo debemos 
https://doi.org/10.15359/ree.24-S.11

https://www.revistas.una.ac.cr/index.php/educare

educare@una.ac.cr

trabajar desde hoy. Generalmente por la premura, nuestras acciones buscan responder a las demandas del momento y olvidamos pensar en las necesidades y requerimientos futuros de la profesión docente.

\section{Desarrollo}

Si bien las tecnologías han estado presentes en los procesos de las instituciones educativas en diferentes contextos desde tiempo atrás, no fue hasta la llegada de la COVID-19 que en forma masiva y en cuestión de pocas semanas, se rediseñaron las asignaturas presenciales para integrar estas tecnologías en los procesos de enseñanza y de aprendizaje. Pero vale la pena preguntarnos: ¿estaban las personas docentes preparadas para enfrentar este cambio? Y más importante aún, ¿estarán listas para los cambios venideros?

Moreira (2005) afirma que si queremos que nuestro estudiantado esté preparado para enfrentarse a una realidad cambiante requerimos del aprendizaje significativo crítico, de manera que logre "lidiar, de forma constructiva, con el cambio, sin dejarse dominar, manejar la información sin sentirse impotente frente a su gran disponibilidad y velocidad de flujo, beneficiarse y desarrollar la tecnología, sin convertirse en tecnófilo" (p. 88). Para ello conviene realizar una integración crítica de las tecnologías emergentes en la formación docente que logre transformar la praxis pedagógica.

Son tecnologías emergentes aquellas que potencialmente disruptivas en los contextos y procesos educativos, comienzan a ser altamente utilizadas, independientemente de que sean nuevas o viejas, pero requieren de investigación educativa (Veletsianos, 2010). Así, muchas personas docentes comienzan a implementar una determinada tecnología sin cuestionarse el por qué y el para qué de su uso en la clase, y qué le está aportando al proceso de aprendizaje de sus estudiantes.

De ahí que en la formación docente se hace necesario cuestionar las prácticas donde se realiza un uso instrumental de las tecnologías, o bien se sustituye una tecnología vieja por una nueva, sin que se modifique o redefina la estrategia de mediación pedagógica implementada (García-Utrera et al., 2014). Podríamos encontrar ejemplos en las prácticas docentes que se han dado durante la pandemia, donde la clase magistral y presencial fue sustituida por una charla de la persona docente por videoconferencia, o bien donde el examen a resolver con lápiz y papel se trasladó a un examen en una herramienta virtual.

Sería oportuno propiciar investigaciones donde se analicen aquellos entornos de aprendizaje, sean virtuales o presenciales, en que la tecnología se convierte en una herramienta para pensar en nuevas formas de enseñar y de aprender, con las cuales podemos dialogar, problematizar, crear, aprender a ser y convivir con otras personas, implementando una evaluación educativa diversa. 
Esto no es un asunto de incluir cursos de tecnologías en las mallas curriculares de las carreras, adonde se enseñe al futuro docente sobre herramientas o recursos didácticos que podría implementar en su práctica profesional. Más bien generar espacios pedagógicos durante su paso por la universidad y por el CIDE, en los que nuestro estudiantado pueda vivenciar una integración crítica de las tecnologías y el profesorado sea el primero en reflexionar sobre la propuesta metodológica empleada y el papel que está jugando la tecnología en ella.

Implica también que dediquemos tiempo a pensar en el futuro y, particularmente, en el futuro de la educación. Es analizar de qué forma la realidad virtual, el internet de las cosas, la inteligencia artificial y otras tecnologías formarán parte del escenario educativo y cómo podremos aprovecharlas para transformar los espacios y las experiencias de aprendizaje. Asimismo, repensar cuál deberá ser el papel de la persona educadora en el futuro, cómo evitar la despersonalización de la educación y lograr que el humanismo se mantenga en los procesos educativos desarrollados por las personas graduadas del CIDE.

\section{Conclusión}

De este modo requerimos realizar acciones de formación donde la integración crítica de las tecnologías emergentes se vivencie en cada uno de los cursos que desarrollamos, dando el protagonismo y la palabra a nuestro estudiantado, invitándole a cuestionar nuestras prácticas y donde construyamos junto a él con mirada en el futuro y pensamiento prospectivo propiciando un verdadero aprendizaje significativo crítico.

Nota general: Corrección de estilo y traducciones a cargo de la autora.

\section{Referencias}

García-Utrera. L., Figueroa-Rodríguez, S. y Esquivel-Gámez, I. (2014). Modelo de sustitución, aumento, modificación y redefinición (SAMR): Fundamentos y aplicaciones. En I. Esquivel-Gámez (Ed.), Los Modelos Tecno-educativos: Revolucionando el aprendizaje del siglo XXI (pp. 205-220). DSAE-Universidad Veracruzana. https://www.researchgate. net/publication/273754983 Modelo de Sustitucion Aumento Modificacion y Redefinicion SAMR Fundamentos y aplicaciones

Moreira, M. A. (2005). Aprendizaje significativo crítico. Indivisa. Boletín de Estudios e Investigación, 6, 83-102. https://www.redalyc.org/articulo.oa?id=77100606

Veletsianos, G. (2010). A Definition of emerging technologies for education. En G. Veletsianos (Ed.), Emerging technologies in distance education (pp. 3-22). Athabasca University Press. 